Australian Journal of

Educational Technology

\title{
Design issues in computer-based education
}

\author{
Keith Rees \\ Deakin Australia, Deakin University
}

\begin{abstract}
The merits and demerits of computer multimedia within the domain of CBE is a topical discussion point. Dan Ellis has recently argued a case for 'barefoot multimedia' based on his experience developing CBE at Queensland University of Technology (Ellis, 1994). The following article briefly relates some of the CBE development work taking place at Deakin University and takes issue with some of the points made by Ellis.
\end{abstract}

In a paper presented to the IFIP conference in August 1994, Dan Ellis presented a brief history of CBE at QUT. 'Since its inception in 1986, CBE at QUT has developed a strategy for success in exploiting computers to help students' learning outcomes.

QUT has adopted a return on investment (ROI) approach which Ellis summarises by saying, 'We aim to provide conveniently, cheaply, and reliably, for very large numbers of students whenever possible, learning experiences that cost little to produce, that catalyse the reaction between student and existing learning resources, that induce active involvement by the student, and that enable lecturers to track the progress of individuals in very large classes.'

The resulting $\mathrm{CBE}$ products frequently take the form of text based programs which reflect a 'Socratic process' of learning.

This rationale is provided in response to recent (unwelcome) pressure Ellis has apparently experienced at QUT from teaching staff clamouring for multimedia in CBE: 'Just when we thought we had it all solved, along comes chaos in the form of multimedia. Text based question and answer just doesn't look the same without sound, movement, and video ... (which) 
causes havoc for our ROI approach.' Ellis then looks at the issues surrounding multimedia use in universities' educational goals - when is it appropriate and when not? He argues that:

- while multimedia 'stuff' is more interesting, exciting, and absorbing, it is no more effective than text based CBE in bringing about better, longer lasting learning outcomes

- the nature of multimedia makes it easier than with text to develop materials that are low on Bloom's taxonomy. 'With multimedia ... the educational strategy has taken a back seat, forced there by the multisensory imperatives of the media available to the developer.'

He concludes by drawing a parallel between barefoot medicine in poor countries and 'barefoot multimedia' ('a minimalist approach to CBE') and argues that both approaches are appropriate to the needs and resources of third world health care and educational provision in the advanced world respectively.

\section{Development issues for CBE}

Ellis does CBE a disservice by presenting development options in 'either/or' terms. It is blinkered, to say the least, to characterise drill and practice CBE as being based on learning needs and difficulties of students and desired learning outcomes, while multimedia CBE is said to place educational strategy in 'a back seat, forced there by multi sensory imperatives of the media available to the developer'.

There is good and bad in multimedia CBE as there is in drill and practice (and as there is in print, video, classroom instruction, and any other form of educational presentation).

Furthermore, Ellis' dichotomy distracts attention from the continuum of forms of CBE. While the drill and practice produced at QUT and his caricature of multimedia may represent opposite ends of the spectrum, there is a range of further options in between. These mid-range Options may incorporate elements of drill and practice, text based exposition, simulation, hypertext branching options, and may use 'multimedia' techniques to some extent.

Ellis has a point regarding the relative cost structures of multimedia as opposed to his more pedestrian style of operation. However, it really is a question of horses for courses. There is a place for varying degrees of 
sophistication in the field of CBE and cost is but one consideration in deciding the approach to be taken in any particular development situation. The Ellis view is in danger of making a virtue of the economical but mundane electronic page turning approach to CBE to the exclusion of any effective enhancements. The opposite end of the argument would dismiss lower cost approaches to CBE as being ideologically unsound and wasteful uses of the processing power of the computer.

Irrespective of ideology, white greater programming complexity does result in greater cost, hardware and software developments are reducing the cost differential between the lower and higher order approaches to CBE.

Accordingly, the style of program adopted should be appropriate in the circumstances. This leaves the options very wide and open to negotiation in view of the resources available for development.

From the design point of view, other relevant issues are that:

- it is difficult to read and absorb dense text on a computer screen (certainly more difficult to read than the same density of text on paper).

- strictly linear programs which are parodied as electronic page turning can quickly become tedious and may not represent much of an advance on the printed presentation of the same material.

- simulation and other higher order forms of CBE are inherently more interesting and allow, for greater user control of the program than drill and practice programs.

\section{CBE at Deakin}

Deakin University has recently expanded its CBE development activity in relation to both internal university programs and programs for client organisations (through Deakin Australia, the University's commercial arm).

A number of developments have been undertaken in the accounting/ business area where CBE is regarded as offering a teaching/learning strategy with significant advantages over existing print and other learning resources. The programs incorporate a variety of approaches to CBE although none are 'multimedia' in the sense of using sound and/or video inputs.

Some of the programs are outlined below. 


\section{The statement of cash flows}

This program was developed for the Australian Society of Certified Practising Accountants and forms part of the compulsory core of the CPA Programme. It teaches the background to and requirements of Accounting Standard AAS 28 and provides practical exercises in preparing the statement of cash flow and related accounting work sheets and other calculations.

The approach used combines extensive electronic page turning (to present descriptive explanation of relevant concepts and principles) in conjunction with numbers of exercises using an active spreadsheet which is embedded in the program. Screen text was pruned to some extent since the program was designed for use in conjunction with a printed study guide. An extensive text based help file is also provided which is accessible from any part of the program and which serves to reduce the amount of text presented in the main body of the program.

The spreadsheet exercises allow users flexibility in studying cash flow through the computer program. After data is entered, work may be assessed and initial feedback obtained. Users may then return to the exercise to amend work, call up more detailed explanations, refer to the related help files, or call up the solution to the problem.

A section of the program presents a multiple choice test on the content which is pitched at the level of the end of semester examination.

\section{The Taxation Training Program}

The Taxation Training Program is a simulation program which presents a series of case study exercises. The program functions as a simulated dialogue between a tax accountant (the user) and a number of clients (the computer). After logging on, the user (as the tax accountant) is required to question the computer to find out the details needed to enter into the tax return of the chosen client. The tax form is presented as an active spreadsheet embedded in the program.

The tax accountant asks questions by selecting question keywords. Subquestion keywords which appear in relation to selected keywords allow further detail to be checked. The computer supplies answers to questions from the prepared client data base. Answers are then used to record data on the client's tax return. 
Branching options provide access to a depreciation worksheet, relevant tax documents, and rebate forms and other schedules.

When the tax return is completed, the tax accountant has the return reviewed by the tax manager. This provides a summary of the time taken to prepare the return and the number of errors made.

A context sensitive help file is available and the user has an opportunity to review and amend the tax return before the second assessment by the tax manager, after which explanations for individual calculations and the solution to the whole exercise may be called up.

\section{Introduction to Accounting}

This program introduces accounting concepts and procedures through an essentially linear, text based expository presentation.

Practical exercises using the embedded spreadsheet function are included to involve the user in the process but there is less interaction in this program than the other programs described here. Exercises serve to confirm mastery of the principles presented as the user is introduced to the accounting equation and led through a cumulative process of refining the equation and devising associated rules and procedures.

\section{General ledger program}

This program covers the range of topics taught in first year accounting and presents an integrated recording environment to test users' mastery of bookkeeping procedures including ledger preparation, balance day adjustments, and presentation of final reports.

The program does not provide textual exposition of the subject matter: this is covered in printed study guides and lecture / tutorial presentations. The purpose of the program is to provide a flexible mechanism for users to apply theory and test mastery.

The active spreadsheet embedded in the program uses a randomising function to generate an infinite number of practical exercises to present case studies, assess users' work, provide useful feedback, and present solutions to each randomly generated problem. 


\section{Consolidation accounting}

Consolidations is an area of accounting which is regarded by teachers as being conceptually difficult to teach. The consolidations program uses the active spreadsheet embedded in the program to present a reporting shell containing a worked illustration and a comprehensive set of case study data with a randomising function. Users are able to specify particular consolidation issues to be included or excluded before generating case study exercises to work on. An infinite number of unique exercises may be generated using the randomising function.

There is very little descriptive text in the program which is designed to be used in conjunction with a printed study guide. The computer program enables users to apply the theory contained in the text and acquire the procedural reporting skills by working intensively on case studies and reviewing computer generated feedback on their progress. The program also contains routines which explain the derivation of key figures in the case studies.

\section{Future projects}

A number of projects are planned for development in 1995 and 1996 including foreign currency translation, risk management in corporate treasury dealings, case studies in insolvency administration and performance auditing, and a multiple choice test question program applicable to any subject area.

Thus far, Deakin has used a combination of text exposition, drill and practice, and simulation, with very limited use of 'multimedia' techniques. We have found that extensive presentation of text does not work well on screen and is not popular with users. Deakin has a long history of presentation of high quality print material which is where extensive text is best placed. Another useful option has been to place longer text sections in context sensitive help files which are able to be accessed from any part of the interactive programs.

The emphasis in future development work is likely to be in simulation, the development of program shells, and the use of randomising functions which the 1994 user feedback suggested were the most successful aspects of Deakin's CBE development and which we perceive to offer the greatest educational potential - particularly when used in conjunction with print and other existing educational resources. Moreover, authoring approaches 
are now available which reduce the development to runtime ratio considerably for the types of programs we are developing.

Ellis stresses that the QUT approach takes as axiomatic that 'it is the student that is intelligent, not the computer' (author's emphasis). While we recognise that $\mathrm{CBE}$ should be designed around intelligent participation by the user, Deakin projects rely on the computer providing an intelligent contribution well. In some cases the computer is breathtakingly intelligent.

Deakin will continue to use drill and practice where it is deemed appropriate, that is, where computer presentation offers significant advantages over presentation of the same content as printed text. We envisage the progressive introduction of sound and video (where appropriate) in future development work as CD ROM enhanced computers become more widely available.

\section{Conclusion}

When faced with the 'overwhelming desire of lecturers to get into multimedia', Ellis (and the rest of us) should heed the words of Socrates as he opened his inaugural CBE: (Colloquium based education) workshop on the steps of the Parthenon all those years ago ...

'Does your proposed approach:

- address the learning need

- meet the expectations of the target learners

- enable learners to do things they can't do using existing resources

- motivate the learners to interact with the program and other learning resources

- place control in the hands of learners as far as is possible within the parameters of the program

- fall within the budget constraints of the developing organisation?'

Oddly enough, this advice bears a remarkable similarity to Ellis' rules of thumb for ensuring development of a 'product that does a decent job'. The point of divergence, however, is that 'barefoot multimedia' is one of many development options to be considered rather than, as Ellis suggests, the only option to present itself. 


\section{Clarifying note}

The Federated Teachers Union of Victoria journal some years ago presented a number of extracts from student answers to history examination questions. The following item bears on discussion in this article and may help to clarify some of the issues for readers.

'Socrates was a famous Greek teacher who went around giving people advice. They killed him. Socrates died from an overdose of wedlock.'

\section{Reference}

Ellis, D. (1994). Barefoot Multimedia, Or, All is Not What it Seems, Moriarty. Presented to the International Federation of Information Processing TC3/ Working Group 3.2 Working Conference, Interactive multimedia in university education: Designing for change in teaching and learning, held at the University of Melbourne from 6 to 8 August 1994.

Contributor: Keith Rees is an instructional designer at Deakin Australia, the commercial arm of Deakin University. He was the instructional designer and project manager for one of the CBE projects discussed in this article. His address is Deakin Australia, Professional Education Division, Deakin Australia, Geelong, Victoria, 3217, Australia.

Please cite as: Rees, K. (1995). Design issues in computer-based education. Australian Journal of Educational Technology, 11(1), 28-35.

http: / / www.ascilite.org.au / ajet/ajet11/rees.html 